\title{
Impact of orocecal transit time on patient's perception of lactose intolerance
}

\author{
Francesc Casellas, Anna Aparici, Maite Casaus, Purificación Rodríguez and Juan R. Malagelada \\ Digestive System Research Unit. Hospital Universitari Vall d'Hebron. Ciberehd. Barcelona, Spain
}

\begin{abstract}
Background: symptoms attributed to the lactose intolerance are an important public health issue because of their prevalence and social relevance. Also because they may cause undue rejection of dairy products consume with potential health consequences. Transit time is a putative factor implied in the severity of symptoms associated with lactose.

Objectives: to elucidate the relation between orocecal transit time (OCTT) and lactose intolerance symptoms.

Methods: observational study in patients referred to a lactose hydrogen breath test who showed an increase in breath $\mathrm{H}_{2}$ excretion higher than $25 \mathrm{ppm}$. OCTT was measured with the breath test and symptoms of lactose tolerance with a validated scale. Symptoms were measured twice: before receiving the lactose, inquiring about self perceived symptoms when patients consumed dairy products at home ("home symptoms"), and again after completing the lactose breath test ("test symptoms").

Results: 161 patients were included. There was no correlation between OCTT and home symptoms $(r=-0.1)$. When OCTT was faster than 60 minutes, intensity of "test symptoms" was similar to "home symptoms". However, in patients with normal or slow OCTT, the "home symptoms" were more intense than the "test symptoms" ( $p<0.05$ ). At home, symptoms were independent of OCTT but with the lactose test load the symptoms were proportionately more intense with faster OCTT.

Conclusions: in lactose maldigesters, selfreported symptoms of lactose intolerance are more pronounced at home than after a high lactose challenge. Intolerance symptoms that patients attributed to lactose consume at home are due to factors other than fast OCTT.
\end{abstract}

Key words: Lactose intolerance. Lactose malabsorption. Hydrogen breath test. Lactase activity. Transit time. Orocecal transit time.

This work was supported in part by grants from the Generalitat de Catalunya (RE: 2001SGR00389) and Centro de Investigación Biomédica en Red de Enfermedades Hepáticas y Digestivas (Ciberehd, Spain).

Received: $20-08-2012$

Accepted: 19-12-2012

Correspondence: Francesc Casellas. Digestive System Research Unit. Hospital Universitari Vall d'Hebron. Pso. Vall d'Hebron, 119. 08035 Barcelona, Spain e-mail: fcasellas@vhebron.net

\section{INTRODUCTION}

Adult lactase ("lactase-phlorizin hydrolase") deficiency and lactose maldigestion are frequent, affecting one-third of the population of (1-4). In lactose maldigesters, consume of lactose containing dairy products may induce symptoms that include abdominal distention, flatulence, abdominal cramping and diarrhea. Symptoms of lactose intolerance are, at least in part, related to the amount of unabsorbed lactose, but there is a discrepancy between symptoms that patients attribute to lactose intolerance and symptoms elicited by a large lactose load in the laboratory (5). Variations in small bowel transit time may partially explain the commonly observed inconsistency between self-perceived lactose intolerance, objective lactose-elicited symptoms and lactase activity (6-8). True lactose maldigesters with diarrhea tend to have a fast orocecal transit time (9). It has also been suggested that when lactase deficient patients consume fermented milk treated with probiotics, refer less intense symptoms in parallel with a delay in orocecal transit time (10). Another study in patients with genetically determined low lactase activity, who received of lactose, showed that lactose intolerant patients have a shorter orocecal transit time than tolerant, but transit time was not related with the presence of diarrhea (11).

The purpose of the present study was to evaluate in lactose maldigesters the influence of transit time on self-reported lactose intolerance symptoms, as perceived in the usual home conditions, and after a lactose challenge in the laboratory. To this end, symptoms believed to be caused by lactose intolerance were evaluated in a group of patients with demonstrated lactose malabsorption with the lactose

Casellas F, Aparici A, Casaus M, Rodríguez P, Malagelada JR. Impact of orocecal transit time on patient's perception of lactose intolerance. Rev Esp Enferm Dig 2013;105:13-18. 
breath test. Patients described their symptoms as perceived under usual conditions at home ("home symptoms") and after a large oral load of lactose ("test symptoms") in the laboratory.

\section{METHODS}

\section{Patients}

Patients referred to our Digestive System Research Unit for evaluation of suspected lactose maldigestion were prospectively informed about the study and provided informed consent. None declined to participate in the study. Exclusion criteria included a previous history of gastrointestinal surgery or previous ingestion of antibiotics or preparation for radiologic or endoscopic examinations for at least two weeks prior to entering the study. Both patients with primary or secondary lactose malabsorption were included. Only patients who exhibited a positive lactose-HBT were included in the study. One hundred sixty one Caucasian patients (58 men, 103 women; median age: 38 years) with a positive hydrogen breath test (HBT) fulfilled the criteria to be included in the analysis.

To measure the intensity of lactose intolerance symptoms, patients completed a validated specific symptoms questionnaire (12) on two occasions. First before the lactose-HBT, being asked about symptoms they related to usual consumption of milk based products at home ("home symptoms"). Second, at the end of the lactose-HBT, being asked about symptoms they may have experienced after the ingestion of a lactose test load ("test symptoms"). The standard lactose dose, equivalent to 1 litre of milk, was chosen because it clearly discriminates between lactose absorbers and maldigesters, based on hydrogen production (13).

\section{Procedure}

\section{Hydrogen breath test}

The lactose-HBT was performed as described previously $(5,13)$. Following a standardized low-carbohydrate dinner, overnight fast and thorough brushing of the teeth, end-expiratory breath samples were obtained before and at 30-min intervals after the lactose load at room temperature for the ensuing 3 hours. Breath samples were collected in hermetic bags fitted with a three-way valve (GaSampler ${ }^{\circledR}$, Quintron Instruments). During the test, patients were instructed to remain seated. Eating, smoking and exercising were not allowed during the test. No medications that could modify transit time were allowed during the test.

Hydrogen concentration was determined in breath samples by chromatographic analysis (Quintron model 12i Microlyzer ${ }^{\circledR}$ ) and expressed as maximal increase over baseline concentration in parts per million (ppm). In all study patients the increase in hydrogen above basal levels was greater than $25 \mathrm{ppm}$ that was the cut-off validated for the detection of lactose malabsorption, with a sensitivity of 95\% (13) and a calculated positive predictive value for Spanish population of 0.89 .

\section{Symptoms questionnaire}

A validated self-administered questionnaire for lactose intolerance (12) was used for symptom assessment both of home symptoms and test symptoms. In short, the questionnaire includes five items (diarrhea, abdominal cramping, vomiting, audible bowel sounds and flatulence). Symptom severity was self-rated by subjects on a $10-\mathrm{cm}$ visual analogue scale ranging from 0 (without symptoms) to 10 (maximum symptoms). The total score on the questionnaire was obtained as the sum of the individual results of the 5 visual analogue scales. Thus, the total score on the symptom test ranged from 0 to 50 .

\section{Orocecal transit time}

The protocol required that all study patients were hydrogen producers, defined as an increase in hydrogen excretion over 10 ppm during the 3-hour test (14). The OCTT was defined as the time interval between ingestion of lactose and the first increase in hydrogen above basal levels over $3 \mathrm{ppm}$, provided that the increase was sustained for at least three consecutive determinations (15). The magnitude of hydrogen increase after the lactose load was calculated on the basis of the maximum peak increase on hydrogen excretion. The measurement of the OCTT was performed with the lactose-HBT, without addition of lactulose or another unabsorbable carbohydrate (16), because in lactose maldigesters the lactose itself acts as a nonabsorbable carbohydrate and because it allows to compare symptoms and transit time with the same substrate. The intention of the study was to determine whether an accelerated or delayed OCTT influences the intensity of symptoms. Furthermore, the strategy of using milk lactose or lactose- ${ }^{13} \mathrm{C}$ ureide as a breath substrate to measure OCTT instead of the more usual substrate, lactulose, has also been validated by others $(17,18)$. Criteria used in this study are similar to criteria applied in other studies that measured the OCTT with milk enriched with lactosucrose as substrate. These previous studies defined OCTT as the time interval between milk ingestion and an increase of five or more ppm over baseline levels, which were sustained for at least two consecutive intervals (19). Defining OCTT on the basis of small increases in hydrogen excretion seems more precise than using larger increases (20).

\section{Statistical analysis}

Variables were described as median and 25-75\% quartiles. Differences between medians were calculated with 
Table I. Results of the symptom questionnaire according to the orocecal transit time in minutes. Scoring of home symptoms questionnaire was unrelated with the OCTT. However, according to the Kruskal-Wallis one way analysis of variance on ranks, symptoms after $\mathbf{5 0} \mathrm{g}$ lactose load in the lab were significantly more marked in those patients with faster OCTT. Results are expressed as median values for each of the readings

\begin{tabular}{cccc}
\hline OCTT with $50 \mathrm{~g}$ lactose & $n$ & $\begin{array}{c}\text { Symptoms at home } \\
\text { ("home symptoms") }\end{array}$ & $\begin{array}{c}\text { Symptoms after oral 50 g lactose } \\
\text { ("test symptoms") }\end{array}$ \\
\hline $0-60 \mathrm{~min}$ & 95 & 23,0 & 23,0 \\
$61-120 \mathrm{~min}$ & 47 & 17,0 & $15,0 *$ \\
$121-180 \mathrm{~min}$ & 13 & 19,0 & $11,0 *$ \\
$>180 \mathrm{~min}$ & 6 & 26,0 & $7,0 *$ \\
\hline
\end{tabular}

$*=p<0.05$ test symptoms after lactose load vs. home symptoms.

the Wilcoxon signed rank test or the Kruskal-Wallis one way analysis of variance on ranks test. Correlation between quantitative variables was analyzed with the non-parametric Spearman correlation test. Accepted level of statistical significance was lower to 0.05 .

\section{RESULTS}

\section{Lactose breath test assessment}

Lactose-HBT was abnormal (delta increase over 25 ppm) in all 161 patients, participants being exclusively lactose maldigesters with an abnormal lactose-HBT. Median maximum increase in hydrogen excretion after the oral $50 \mathrm{~g}$ lactose administration was 96.0 [63.7-145.0] ppm.

\section{Assessment of OCTT relation to symptoms}

Median OCTT was 60.0 [60.0-90.0] minutes, time shorter to the mean 80.0 minutes obtained in the technique validation studies (16). The OCTT was significantly inversely correlated with the peak increase in hydrogen excretion (Spearman Rank Order Correlation $r=-0.47$, $\mathrm{p}<0.001)$, being the OCTT shorter as higher the increase in hydrogen excretion. OCTT was also inversely corre-

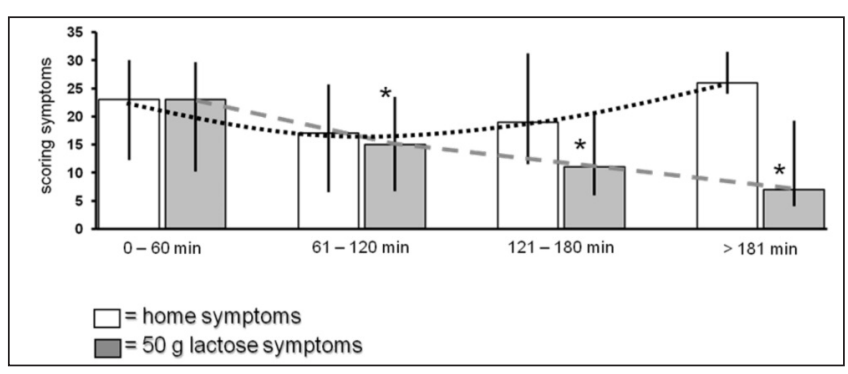

Fig. 1. Results of the symptoms scoring at home or after $50 \mathrm{~g}$ lactose load in the lab in medians and percentiles, depending on the transit time. Differences between home symptoms and symptoms evoked by lactose load are more marked as slower is the transit time, as shown by the divergent trends between the dotted black (home symptoms) and the grey (lactose symptoms) lines. Height of the bars indicates medians and ranges show 25 to 75 percentiles ( ${ }^{*}=p<0.05$, Wilcoxon signed rank test). lated with the intensity of symptoms manifested after lactose load in the lab $(\mathrm{r}=-0.21, \mathrm{p}<0.01)$. The symptom best related with OCTT after lactose load was audible bowel sounds $(\mathrm{r}=-0.22, \mathrm{p}<0.01)$ and the less correlated was flatulence $(r=-0.08, p=N S)$. By contrast, there was a lack of correlation between the intensity of reported symptoms at home and the OCTT for total symptoms score $(r=-0.08, p=N S)$ as for each symptom analyzed by the questionnaire.

Results of the questionnaire scores reflecting symptoms at home and symptoms after the lactose load are shown in Table I together with the OCTT. Scoring of the home symptoms questionnaire was non-significantly different in patients with fast (0-60 min), normal (61-120 min) or slow OCTT (> $180 \mathrm{~min}$ ). However, according to the KruskalWallis one way analysis of variance on ranks, symptoms after the lactose load observed in the laboratory were significantly more marked in those patients with faster OCTT (Table I), from a score of 23.0 [10.2-29.7] in patients with OCTT faster than 60 minutes to a score 7.00 [3.5 to 19.2] in patients with OCTT slower than 180 minutes. As a consequence of the differences on symptoms perception at home or after lactose load depending on the OCTT, differences between home and test symptoms were more marked as more slowly was the transit time (Fig. 1).

\section{DISCUSSION}

To expand the knowledge of the complex relationship between symptoms and lactose malabsorption, we undertook the present study which aimed to determine the influence of OCTT on symptoms self-reported by patients when consuming dairy products at home, and compare them with the symptoms elicited by a high-dose lactose challenge in the lab, using a validated short 5-item symptoms questionnaire. In a group of patients with a positive $50 \mathrm{~g}$ lactose-HBT (increase in hydrogen excretion higher to $25 \mathrm{ppm}$ ), as previously validated in our laboratory (12), we correlated the symptoms with the transit time determined as the time elapsed from lactose ingestion to first detectable increase in hydrogen excretion. Main finding of the study is that, in controlled situations and after a lactose load, patients with lactose malabsorption refer symp- 
toms that are much more intense as shorter is the OCTT. That observation could be related with a shortening of OCTT due to the osmotic effect of the unabsorbed lactose. However, it is remarkable that when the same lactose malabsorber patients are asked about the intensity of symptoms experienced at home at usual conditions, the pattern is different because home symptoms are not related with OCTT. This may be relevant because the symptoms referred by patients when consult their physician could be due to other factors than the lactose maldigested itself.

Our results confirm previous studies that suggest a discrepancy between symptoms that patients attributed to lactose intolerance and symptoms elicited by a large lactose load in the laboratory (5). The present analyzes whether in lactose maldigesters the intensity of symptoms experienced in the normal home setting and after ingesting a challenge dose of lactose in the controlled laboratory are related with OCTT. Results of present study clearly show that after oral lactose challenge in the laboratory patients with lactose malabsorption refer symptoms that are more marked as shorter is the transit time. Presumable, the osmotic effect of malabsorbed lactose is the common link between short OCTT and symptom severity when evaluated after the test in the laboratory. However, symptoms referred at home not only are not more intense as faster is the transit time but are even worse as more slow is transit time. These observations about the different symptomatic pattern at home or at laboratory suggest that fast OCTT does not play a key role in the perception of lactose intolerance symptoms that lactose maldigesters refer at home in conditions of usual dairy consume, and reinforce previously published reports (21).

Our observation of the correlation between the lactose challenge test and provocation of symptoms in maldigesters, may also serve as explanation to the response to the symptomatic treatment slowing down transit time. To improve the tolerance to lactose it has been suggested a strategy based on the slowing of the gastric emptying or the intestinal transit time (22), induced by the ingestion of whole milk, changing post-prandial posture or pharmacologically. In lactose maldigesters, loperamide improves symptoms after $25 \mathrm{~g}$ lactose challenge, although it is not recommended as a monotherapy because it increases expense and has potential side effects (23). In a similar manner, propantheline given before ingestion of $50 \mathrm{~g}$ lactose improves clinical symptoms in lactose maldigesters (24). Propantheline slows intestinal transit time and it was observed that the resulting decrease in hydrogen production parallels the improvement in symptoms. That reduction in hydrogen excretion could be related with the delayed transit itself because it also has been observed in subjects after lactulose load when pretreated with loperamide (25). However, the effect of pharmacologically-induced prolongation of transit time on tolerance of lactose by maldigesters has not been established.

The relevance of our observations relates to that symptoms associated with lactose intolerance in the normal home setting are independent of the orocecal transit time. In lactose maldigesters challenge with $50 \mathrm{~g}$ lactose induce symptoms that are inversely related with OCTT but these results are not extrapolable to what patients refer at home in usual conditions. Only in patients with the shortest OCTT after the lactose load in the laboratory are "home symptoms" similar in magnitude to "test symptoms". It is conceivable that this particular subgroup of patients represents the most severe lactose maldigesters and as such report similar intensity of symptoms at home and in the controlled environment of the laboratory. At the other end of the spectrum, patients with the longest transit time after lactose report the mildest symptoms in the lab and the most severe symptoms at home. We speculate that such patients experience symptoms after dietary products at home that are amplified by unknown factors, including psychological and social factors. However, these were not quantified in the present study.

In the lab, we measured simultaneously transit time and symptoms, employing the same substrate challenge. This approach is appropriate since, had we measured transit time on a separate day using a different substrate, i.e. lactulose, the comparison between symptoms and transit would have been less direct and potentially influenced by day to day variability. As indicator of unabsorbed substrate reaching the colon, we used the first detectable increase in breath hydrogen ( $3 \mathrm{ppm})$. This is a relatively small rise but within the accuracy range of the hydrogen detector. Furthermore, to prevent spurious measurements we required that the hydrogen excretion increased further in subsequent 30 minute repeat readings. We cannot exclude the possibility that early hydrogen breath increases were due to small bowel overgrowth, but it is unlikely that in any case it would have occurred in a substantial number of participants.

In conclusion, there is a significant difference between reported symptoms of lactose intolerance under home conditions and symptoms after the lactose challenge test. Patients who manifest intense symptoms associated with rapid transit time are most likely to report comparable symptoms when exposed to dairy products in the home setting. These observations are clinically relevant and may help improve management of patients who regard themselves as lactose intolerant.

\section{REFERENCES}

1. Peña A, Peña JF. Malabsorción de lactosa en estudiantes españoles. Tolerancia intestinal a la sobrecarga oral de lactosa. Rev Esp Enferm Dig 1971;35:925-38.

2. Carnicer J. Malabsorció de lactosa en una població preescolar i escolar. But Soc Cat Pediatr 1993;53:26-32.

3. Vázquez C. Malabsorción de los hidratos de carbono en el niño: malabsorción de la lactosa. An Esp Ped 1975;8:166-78.

4. Leis R, Tojo R, Pavón P, Douwes A. Prevalence of lactose malabsorption in Galicia. J Ped Nutr 1997;25:296-300.

5. Casellas F, Aparici A, Casaus M, Rodríguez P, Malagelada JR. Subjective perception of lactose intolerance does not always indicate lactose malabsorption. Clin Gastroenterol Hepatol 2010;8:581-6.

6. Martini MC, Savaiano DA. Reduced intolerance symptoms from lactose consumed during a meal. Am J Clin Nutr 1988;47:57-60.

7. He T, Priebe MG, Harmsen HJ, Stellaard F, Sun X, Welling GW, et al. Colonic fermentation may play a role in lactose intolerance in humans. J Nutr 2006;136:58-63. 
8. Hirota N, Sone Y, Tokura H. Effect of post-prandial posture on orocecal transit time and digestion of milk lactose in humans. J Physiol Anthropol Appl Human Sci 2004;23:75-80.

9. Fernández-Bañares F, Villá S, Esteve M, Roca M, Cabré E, AbadLacruz A, et al. Acute effects of abdominopelvic irradiation on the orocecal transit time: its relation to clinical symptoms, and bile salt and lactose malabsorption. Am J Gastroenterol 1991;86:1771-7.

10. Gaón D, Doweck Y, Gómez Zavaglia A, Holgado A, Oliver G. Lactose digestion by milk fermented with Lactobacillus acidophilus and Lactobacillus casei of human origin. Medicina (B Aires) 1995;55:237-42.

11. Vonk RJ, Priebe MG, Koetse HA, Stellaard F, Lenoir-Wijnkoop I, Antoine JM, et al. Lactose intolerance: analysis of underlying factors. Eur J Clin Invest 2003;33:70-5.

12. Casellas F, Varela E, Aparici A, Casaus M, Rodríguez P. Development, validation and applicability of a symptoms questionnaire for lactose malabsorption screening. Dig Dis Sci 2009;54:1059-65.

13. Casellas F, Malagelada JR. Applicability of short hydrogen breath test for screening of lactose malabsorption. Dig Dis Sci 2003;48:1333-8.

14. Casellas F, Torrejón A, Vilaseca J, Aparici A, Casaus M, Rodríguez $\mathrm{P}$, et al. Influence of colectomy on hydrogen excretion in breath. Int J Colorectal Dis 2010;25:485-9.

15. Fort JM, Azpiroz F, Casellas F, Andreu J, Malagelada JR. Bowel habit after cholecystectomy: physiological changes and clinical implications. Gastroenterology 1996:111:617-22.

16. Casellas F, Malagelada JR. Influence of the substrate on the reproducibility of the hydrogen breath test to measure the orocecal transit time. Digestion 1998;59:696-702.
17. Kondo t. Liu F, Toda Y. Milk is a useful test meal for measurement of small bowel transit time. J Gastroenterol 1994;29:715-20.

18. Geypens B, Bennink R, Peeters M, Evenepoel P, Mortelmans L, Maes $\mathrm{B}$, et al. Validation of the lactose-[13C]ureide breath test for determination of orocecal transit time by scintigraphy. J Nucl Med 1999;40:1451-5.

19. Hirota N, Sone Y, Tokura H. Effect of post-prandial posture on orocecal transit time and digestion of milk lactose in humans. J Physiol Anthropol Appl Human Sci 2004;23:75-80.

20. Hirakawa M, Iida M, Kohrogi N, Fujishima M. Hydrogen breath test assessment of orocecal transit time: comparison with barium meal study. Am J Gastroenterol 1988;83:1361-3.

21. He T, Priebe MG, Welling GW, Vonk RJ. Effect of lactose on orocecal transit time in lactose digesters and maldigesters. Eur J Clin Invest 2006;36:737-42.

22. Montalto M, Curigliano V, Santoro L, Vastola M, Cammarota G, Manna $\mathrm{R}$, et al. Management and treatment of lactose malabsorption. World J Gastroenterol 2006;12:187-91.

23. Szilagyi A, Torchisky A, Calacone A. Possible therapeutic use of loperamide for symptoms of lactose intolerance. Can J Gastroenterol 2000;14:581-7.

24. Peuhkuri K, Vapaatalo H, Nevala R, Korpela R. Influence of the pharmacological modification of gastric emptying on lactose maldigestion and gastrointestinal symptoms. Alim Pharmacol Ther 1999;13:81-6.

25. El Oufir L, Flourié B, Bruley des Varannes S, Barry JL, Cloarec D, Bornet $\mathrm{F}$, et al. Relations between transit time, fermentation products, and hydrogen consuming flora in healthy humans. Gut 1996;38:870-7. 